\title{
VIRTUAL INDUSTRY CLUSTERS: FOUNDATION TO CREATE VIRTUAL ENTERPRISES
}

\author{
M. Flores, A. Molina \\ CSIM-ITESM \\ Ave. Eugenio Garza Sada 2501 Sur \\ Monterrey, N.L. 64849 Mexico \\ +52 (8) 358-2000 Ext. 5115, fax:+52 (8) 328-41-23 \\ myrna.flores@gemmc.ge.mx \\ armolina@campus.mty.itesm.mx
}

\begin{abstract}
The world is living a fast changing process, where the creation of strategic alliances is one important result of this continuous change. A new way of doing business where companies can share their core competencies in order to compete in this global and changing economy is the creation of Virtual Enterprises. To enable the formation of Virtual Enterprises, Virtual Industry Clusters (VIC) should be created. After market opportunities are identified, global partners will need to be searched within Virtual Industry Clusters for specific products, business processes or technologies in order to create Virtual Enterprises. In this paper a Methodology for the Creation of Virtual Industry Clusters is proposed and a case study is presented to describe how the methodology has been applied to create VIRPLAS - A Virtual Industry Cluster of Mexican Plastics companies.
\end{abstract}

\section{INTRODUCTION}

A framework was developed by the $\operatorname{COSME}^{1}$ network to better understand how Virtual Enterprises work. This Global Virtual Enterprise Framework divides the operation of Virtual Enterprises in three main business entities: The Virtual Industry Clusters (VIC's), the Virtual Enterprise Broker (VEB) and the Virtual Enterprise (VE) itself (Molina et. al 1998). Each one of these business entities has to perform the following specific tasks and activities in order to create a Virtual Enterprise (Figure 1):

${ }^{1}$ The research group for Virtual Enterprises performed by the University of São Paulo-Brazil, Monterrey Institute of Technology-Mexico; Aachen University of Technology-Germany; University of Saint Gallen (Institute of Technology Management)-Switzerland; University of Venice, Italy and University of Newcastle upon Tyne, England, is called COSME (Cooperation for Small and Medium Enterprises) network. 
1.- Virtual Industry Cluster (VIC): aggregation of companies from diverse industries, with well defined and focused competencies, with the purpose of gaining access to new markets and business opportunities by leveraging their resources.

2.- Virtual Enterprise Broker (VEB): this business entity is responsible for searching opportunities in the global environment and enables the creation of Virtual Enterprises. The Virtual Enterprise Broker performs the processes of partner search and partner selection, and configures suitable infrastructures for VE formation/commitment (physical, legal, social/cultural, information). To achieve its goal the VEB uses the services provided by Virtual Industry Clusters.

3.- Virtual Enterprises (VE): temporary networks of independent companies linked by information technology that share competencies, infrastructure and business processes, with the purpose to fulfil a specific market requirement.

The creation of Virtual Industry Clusters (VIC) is one of the main tasks needed for the creation of Virtual Enterprises. This is because, after Virtual Enterprise Brokers (VIB) identify market opportunities, they will need to search for global partners within the Virtual Industry Clusters database. To deliver the information about possible best partners who can share their core competencies is not an easy task. The Virtual Industry Cluster business entity main product or output is information of partners with core competencies to create Virtual Enterprises. In order to deliver this information, the Virtual Industry Cluster as a business entity needs to search, evaluate, and select possible partners, create the Virtual Industry Clusters and put together all their information in a database. In order to develop a VIC following tasks should be carried out (Flores 1999):

- Identify market needs and trends for product innovation

- Create a model capable of evaluating partners core competencies

- Search for partners who can be interested in sharing their core competencies to create Virtual Enterprises

- Provide support to the VIC members to construct, develop and deploy core competencies

- Develop a Virtual Industry Cluster database were possible partners can be searched by brokers according to their core competencies in products, business processes or technologies.

- Sell the Virtual Industry Clusters core competencies information to the best Virtual Broker once the companies are evaluated and selected.

The complex challenges facing the virtual enterprise include crossing global boundaries established by distance, time, language, political systems and related regulation, new rules of economics, and the new customer and institutional markets (Reid, 96). All of these factors should also be taken in consideration when creating the VIC's.

This paper will describe a methodology, which will explain all the tasks or processes that the VIC business entity needs to perform. A case study of a Virtual Industry Cluster for the plastic industry in Monterrey, Mexico will also be described. 


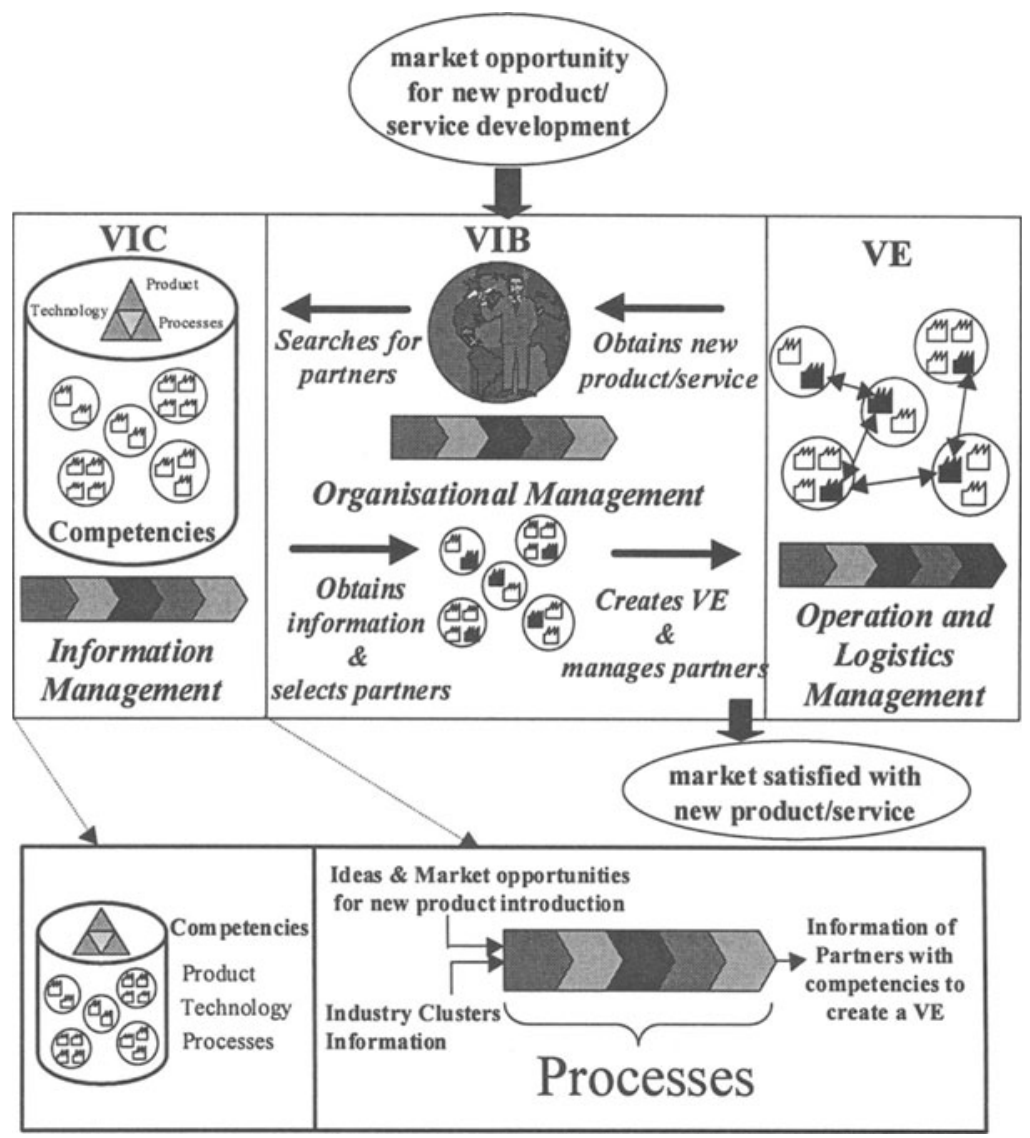

Figure 1. Model for the creation of Virtual Industry Clusters

\section{VIRTUAL INDUSTRY CLUSTERS}

\subsection{Virtual Clusters and Virtual Industry Clusters}

Until now, Industry Clusters are usually created to prove guidance to industry attraction programs with limited resources, and in surfacing areas for improvement in infrastructure and other resources needed by dominant Industry Clusters in a specific region. At the same time the creation of industry Clusters, allows them to obtain ready markets for their products in the province, and the close proximity enables them to tailor their products more readily to the specific needs of the region (Anderson 1994).

On the other hand, Virtual Industry Clusters (VIC) will be created by the aggregation of enterprises around the world with complementary competencies, supported by information technology infrastructure (Molina et. al 1998). The 
creation of new VIC will be focused on the necessity to satisfy market needs and new trends. VEB's will search for partners in the VIC which can put together their core competencies to produce new products. It can be said that Virtual Enterprises will be formed in order to satisfy the market needs for innovation. It is critical to retain and control the firms core competencies, tacit knowledge, and critical parts of the value chain in order to capture the rewards of the market (Chesbrough 1996).

Each partner of the Virtual Enterprise provides some unique skills to it that other wise would not be available. Hence in principle, a Virtual Enterprise should exhibit superior performance by combining best practices. The challenge is to exploit fully this potential (Bertok, 1997). In the authors' opinion, Virtual Industry Clusters will be an evolution of Industry Clusters, and the synergy when deploying the VIC members competencies is one of the main its main strengths. Table 1 shows the differences between Virtual Industry Clusters and Industry Clusters.

\section{Table 1 Industry Clusters vs. Virtual Industry Clusters}

\begin{tabular}{|c|c|}
\hline Intinstri duster & 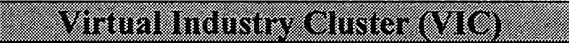 \\
\hline $\begin{array}{l}\text { Clusters are identified using as an important } \\
\text { factor its geographical proximity }\end{array}$ & $\begin{array}{l}\text { Clusters should be identified in a geographically } \\
\text { distributed and global way }\end{array}$ \\
\hline Close physical relationships & $\begin{array}{l}\text { World wide relationships based in state-of-the-art } \\
\text { Information Technologies }\end{array}$ \\
\hline A specific region as an economic system & The world as an economic system \\
\hline $\begin{array}{l}\text { Relationships among its elements are usually } \\
\text { long-term relationships }\end{array}$ & $\begin{array}{l}\text { Relationships are just for one-time to satisfy a } \\
\text { specific need identified by the Virtual Broker }\end{array}$ \\
\hline $\begin{array}{l}\text { Supply Chain Management and Order Fulfilment } \\
\text { are two main business processes, specially for the } \\
\text { buyer supplier relationship. }\end{array}$ & $\begin{array}{l}\text { Innovation management and advanced Supply } \\
\text { Chain Management are two of the main business } \\
\text { process for the success of the Virtual Industry } \\
\text { Cluster }\end{array}$ \\
\hline $\begin{array}{l}\text { Clustering is important to providing guidance to } \\
\text { industry attraction programs with limited } \\
\text { resources and in surfacing areas for improvement } \\
\text { in infrastructure and other resources needed by } \\
\text { dominant industry Clusters in an specific region. }\end{array}$ & $\begin{array}{l}\text { Clustering is important to identify core } \\
\text { competencies (product, business process, } \\
\text { technologies), to satisfy market needs, exceeding } \\
\text { customer expectations and with a global focus. }\end{array}$ \\
\hline $\begin{array}{l}\text { Flow of materials and information are the two } \\
\text { main flows. }\end{array}$ & $\begin{array}{l}\text { Information flow is the main flow, physical flow } \\
\text { of goods will have to be studied in order to select } \\
\text { the geographically closest best partner. }\end{array}$ \\
\hline $\begin{array}{l}\text { Would be able to find ready markets for their } \\
\text { products in the province, and the close proximity } \\
\text { would enable them to tailor their products more } \\
\text { readily to the specific needs of the region } \\
\text { companies. }\end{array}$ & $\begin{array}{l}\text { Virtual Brokers will select partners in the VIC's, } \\
\text { based on their competencies to create a product, } \\
\text { use business processes and technologies to satisfy } \\
\text { a global need based on innovation. }\end{array}$ \\
\hline
\end{tabular}

\subsection{Description of the VIC Main Operations}

The first issue that should be considered to understand the VIC operations is the identification of potential clients. The VIC will have mainly two customers 1) the companies that are members of each cluster and 2) Virtual Enterprise Brokers that search for potential partners to satisfy a need and create a new Virtual Enterprise. The Virtual Industry Cluster business entity will be mainly a service company that has two main objectives: 
1) Invite companies to create new clusters, evaluate them, analyse which are their main strengths and opportunity areas and finally propose the companies (who are now VIC members) improvement projects in order to construct, develop and protect core competencies. These activities should be considered as a continuous improvement cycle.

2) Provide Virtual Enterprise Brokers information about potential partners to create Virtual Enterprises and receive their feedback regarding the partners' performance. Figure 2. Virtual Industry Cluster main operations.

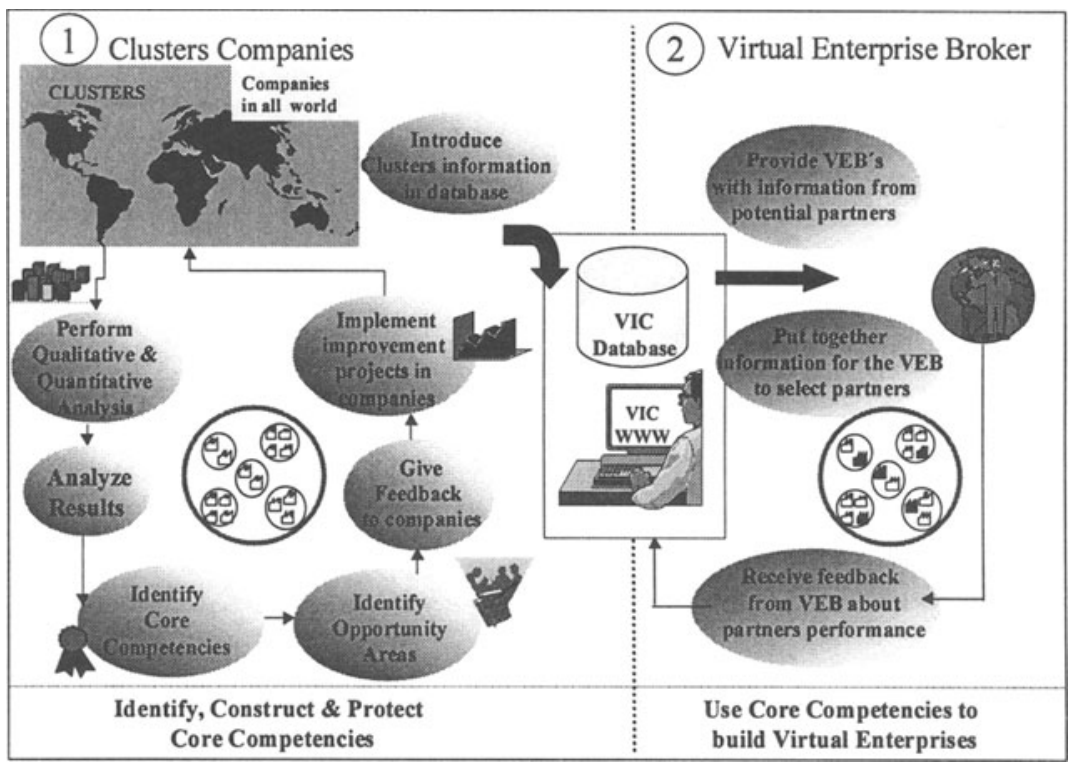

Figure 2. Main activities that the VIC business entity will perform in order to satisfy its main two different clients.

\section{METHODOLOGY FOR THE CREATION OF VIRTUAL INDUSTRY CLUSTERS}

The methodology starts with the new VIC formation and ends with the marketing and selling of possible partners' core competencies information, which is the final product of the Virtual Industry Cluster. Figure 3 shows the four main business processes that will form the methodology, which are: 1) New Virtual Industry Cluster Formation, 2) Virtual Industry Cluster Evaluation and Classification, 3) Virtual Industry Cluster Information Management and 4) Virtual Industry Cluster Selling. These four processes will be explained in detail in this section. 


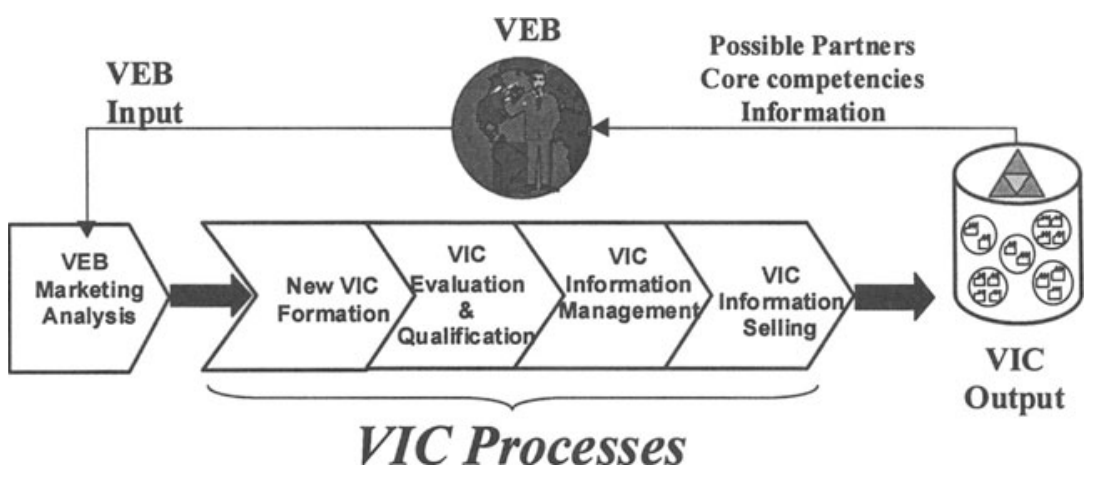

Figure 3. Four main processes to create Virtual Industry Clusters

\subsection{New Virtual Industry Cluster Formation}

The new virtual industry cluster formation is the first process in the methodology to create a VIC. It is important to mention that the VEB will give as input the marketing analysis and it will be assumed that the VEB already detected a need and analysed the market. When the VEB delivers the market analysis to the VIC and asks to create a new VIC, the main objective of this process will be to identify the following three main components:

1) The complete product taxonomy, such as parts, components or/and subassemblies of the product to be manufactured,

2) The business and manufacturing processes needed to produce the new product and

3) Required technologies needed for the development of the new product, from its conception, to its launching.

The virtual cluster formation process will be done by a performing the following five activities: 1) Identify product taxonomy, 2) identify business and manufacturing processes to develop the new product, 3)identify technologies, 4) Search for possible partners that can be part of each cluster, and 5) Create a preliminary business plan for the new VIC creation.

\subsection{Virtual Cluster Evaluation and Qualification}

The first activity to be performed in the second process of the methodology is to contact and visit the identified possible partners. The VIC staff will explain the main objective and benefits of being part of a Virtual Industry Cluster. Once a company accepts, the company is already part of the VIC and a complete evaluation of the company will take place. The evaluation will discover which are the company core competencies and if the company is a potential partner to be able to create a Virtual Enterprise.

The objective of this second process of the methodology is to perform a qualitative and a quantitative evaluation of the company and be able to decide if the evaluated company has core competencies to be part of a Virtual Enterprise. These two evaluations will focus on the product, business processes and technologies of 
the companies. Once the two evaluations are done, the VIC will qualify the evaluated company.

When the product, process or technologies are successfully evaluated in the members of the VIC, their information will be introduced to the VIC database. The next activities are to identify the core competencies and to perform the evaluation of the infrastructures to support the cooperation among enterprises. The VEB will give the minimum required qualitative and quantitative values to decide if the member of the cluster meets the requirements to decide if it has or not core competencies. At the same time, the VEB will give the minimum required for the infrastructures needed to create a Virtual Enterprise.

If an enterprise does not fulfil the requirements, then the company will not be rejected completely to be part of the VIC, it will be a cluster member and it will need to develop core competencies. The company will be qualified according to three things: 1) its qualitative and quantitative evaluation of the product, processes and technologies, 2) its level of core competencies and 3) infrastructures according to the VEB requirements to create a new VIB.

To perform the qualitative and qualitative analysis several tools will be used in the methodology, such as the EFQM ${ }^{2}$ quality model, the ENAPS ${ }^{3}$ benchmarking methodology, process model and performance indicators and a best practices questionnaire (Rogers, 1998).

Regarding the VIC's infrastructure, it is important to assess the information technologies, because the bonding level among them will be high so the VE can succeed. The bonding level indicates the amount of information sharing that has to occur among providers in order for them to carry out a productive interaction (Umar 99).

\subsection{Information Management}

To sell the potential partners information, a very important technological tool is the VIC database. The database will support the operation of the VIC to store and sell the members information. The VIC database will be considered the Information Management System. The information contained in the VIC database should be able to always respond to the following questions to the VEB's : 1) What kind of products the VIC can do? 2) What business processes can it perform? 3) What technologies can be used?

When VEB's want to search for partners in the VIC database, to create Virtual Enterprises to produce a new product, perform or create a new business process or obtain or use technology, he can look for partners it in three following ways: Inside Product Clusters, Inside Business Process Clusters and Inside Technology Clusters.

\subsection{Cluster marketing and selling}

The main goal of this process is to sell the VIC information to the VEB's and obtain Customer satisfaction. During this fourth and last process, the VIC staff will need to

\footnotetext{
${ }^{2}$ EFQM-European Foundation for Quality Management

${ }^{3}$ ENAPS- European Network for Advanced Performance Systems
} 
perform a sales forecasting, identify how and where the information can be sold and which are the best promotion strategies to sell information to the brokers.

The best way in which the VEB can search for partners in the VIC's will be by the creation of a World Wide Web page, which at the same time can allow VEB's from any part of the world to have access to the database and select the best partners for the creation of the Virtual Enterprise.

\section{CASE STUDY: IMPLEMENTATION OF THE METHODOLOGY FOR THE PLASTIC INDUSTRY}

The methodology has been applied to create a new Virtual Industry Cluster for the plastic sector. The given name to the new cluster is VIRPLAS, which stands for VIRtual Industry Cluster for PLAStics. VIRPLAS members were searched in Monterrey, Mexico. The cluster members are Small and Medium Enterprises (SMEs) with high interest in performing global businesses.

To create the new Virtual Industry Cluster, the four processes proposed in the methodology were used. These processes have been further developed into eight main activities. The activities performed were: 1) Select a sector to satisfy an industrial market need, 2) Identify business processes and technological processes needed for the sector, 3) Search for potential partners to deliver products, processes and technologies, 4) Contact and invite potential cluster partners, 5) Receive acceptance from potential partners, 6) Perform a qualitative assessment of the VIC members, 7) Create an enterprise profile for each partner, 8) Publish the new VIC information in the World Wide Web.

One of the most important things to take in consideration when creating a new Virtual Industry Cluster is the interest and commitment of the members to be part of the cluster and participate in the activities needed. During the implementation of the methodology when VIRPLAS was created, a great interest was observed from the participating SMEs to be part of the cluster, to be published in the Internet and to be able to participate in international businesses. It can be said that in order to be successful, members must be willing to participate, they should cooperate when they are being evaluated and show a proactive attitude to obtain a win-win situation. In the case of VIRPLAS, the six members were eager to participate and gave all the needed information and time in order to create the cluster. This commitment was a major enabler to create the cluster successfully.

It is intended, that the creation of VIRPLAS will improve SME competitiveness, by analysing which are the members' main strengths and opportunity areas. Also a set of improvement projects have been envisaged to develop their core competencies and infrastructures to deploy them in the creation of Virtual Enterprises. The creation of the VIRPLAS homepage, will allow brokers to search for potential partners in the plastic industry in Monterrey (Figure 4). 


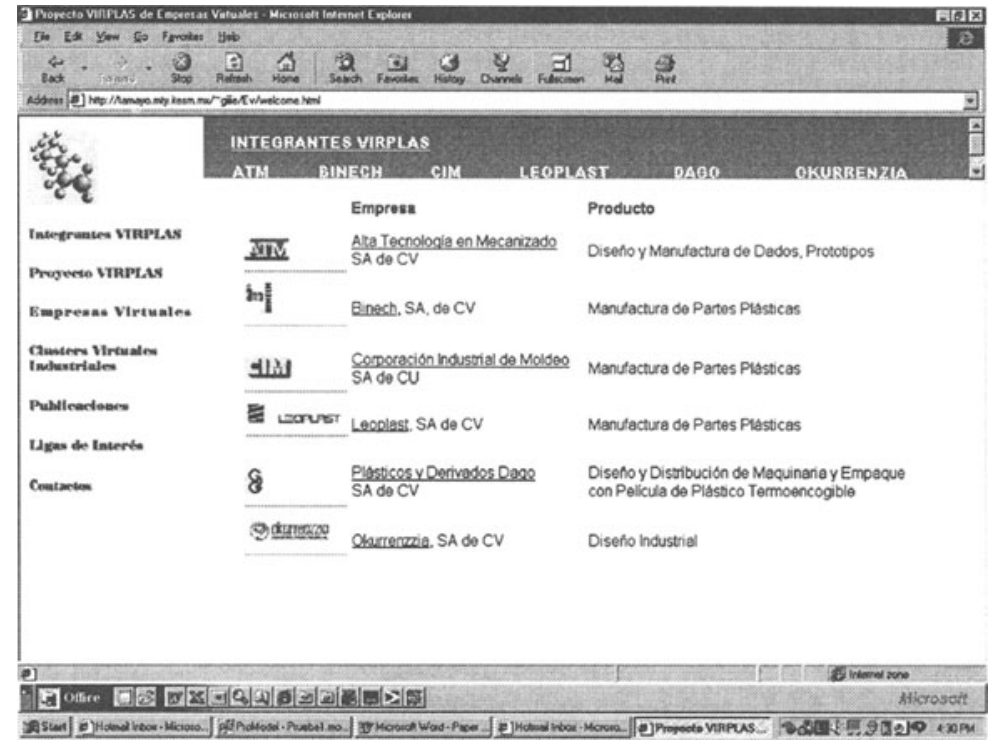

Figure 4. VIRPLAS Homepage (http://tamayo.mty.itesm.mx/virplas)

\section{CONCLUSIONS}

The main objective of the research was to develop a methodology that can be used to create Virtual Industry Clusters in a systematic manner. The authors argue that Virtual Industry Clusters are the foundation for the development of Virtual Enterprises. Brokers need the information from potential partners and if there is a lack of reliable information about manufacturing or service companies, Brokers will face difficulties to configure and create Virtual Enterprises.

It is important to mention that through VICs, Small and Medium companies can be clustered, organised and could have a better chance to be selected by brokers. Therefore, SME's will have the possibility to be integrated in supply chains of Virtual Enterprises.

The success of a VIC relies on the ability of the cluster members to construct, deploy and protect their core competencies continuously. Finally, the creation of Virtual Industry Clusters will enhance the regional development of different industrial sectors by analysing which are their main strengths and opportunity areas in order to implement the enterprise development projects that can construct and develop core competencies of SMEs. These core competencies will be later deployed in the Virtual Enterprise.

It is important to mention that the objective of the creation of Virtual Industry Clusters is not only to deliver potential partners information the Virtual Enterprise Broker to create Virtual Enterprises. It also has to do with the construction and development of core competencies of the cluster members. This activity will 
support the regional development and at the same time will allow the VIC staff to sell the information from the best potential partners.

The creation of VIRPLAS is a first step to demonstrate the importance of the concept of Virtual Industry Cluster. It represents an enormous opportunity in Monterrey, taking in consideration its closeness to the American boundary and the need to manufacture plastic parts and products for market needs in this area. It can be said that the creation of VIRPLAS is a good start to a Virtual Enterprise in the plastic sector. Finally, after the creation of VIRPLAS, it can be concluded that the proposed methodology is a very useful tool to create Virtual Industry Clusters.

\section{REFERENCES}

1. Anderson Gary, Industry Clustering for Economic Development, Economic Development Review, 1994.

2. Bertok P., Mantyla M.,McGovern J., Fernandez G., Working Group Report on Information Infrastructures for Global and Virtual Enteprises, IEEE 1997 p 62-66

3. Chesbrough, H.W. and Teece D.J., When is Virtual Virtuous?, Harvard Business Review, January 1996, 65-73.

4. ENAPS, European Network for Advanced Performance Systems, http://www.enaps.com, 1999

5. EFQM, European Foundation for Quality Management, http://www.efqm.org, 1999

6. Flores M., Methodology for the Creation of Virtual Industry Clusters, Masters Thesis research, Instituto Tecnologico y de Estudios Superiores de Monterrey, ITESM, 1999.

7. Molina A., Flores M., Caballero D., 1998, "Virtual Enterprises: A Mexican Case Study", Intelligent Systems for Manufacturing, Multi-Agent Systems and Virtual Organisations, pp. 159-170, Edited by L. Camarinha, H. Afsarmanesh and V. Marik, Kluwer Academics Publishers.

8. Molina A., Ponguta S, C. Bremer, "An Information Model to Represent the Core Competences of Virtual Enterprises”, Research Report, WZL TH-Aachen, July 1997.

9. Molina A., Ponguta S., C. Bremer, Eversheim W., "A Framework for Global Virtual Business", Journal of Agility and Global Competition, 1998.

10. Reid L., Tapp B.,Liles D.,Rogers K.J., Johnson M., An Integarted Management Model for Virtual Enteprises: Vision, Strategy and Structure, IEMC, 1996 pp-522-527.

11. Rogers Hank, Benchmarking Your Plant Against TQM Best-Practices Plants, Quality Progress, Quality Progress, March, pp 49-55, 1998.

12. Umar A., Missier P., A Framework for Analyzing Virtual Enterprise Infrastructure, IEEE. 1999 